\title{
A novel gene expression scoring system for accurate diagnosis of basaloid squamous cell carcinoma of the esophagus
}

\author{
TAKESHI TADA ${ }^{1}$, REIKO HONMA $^{5}$, JUN-ICHI IMAI ${ }^{2}$, ZENICHIRO SAZE $^{1}$, MICHIHIKO KOGURE $^{1}$, \\ SHIGERU MARUBASHI ${ }^{1}$, KAZUHIRO TASAKI ${ }^{3}$, MASAMITU UNAKAMI ${ }^{4}$, JUNJI EZAKI ${ }^{2}$, \\ HIROSUMI TAMURA ${ }^{2}$, AKIRA NISHIKAWA ${ }^{5}$, YUKO HASHIMOTO ${ }^{3}$, SATOSHI WAGURI $^{2}$, \\ SHINYA WATANABE ${ }^{2}$ and MITSUKAZU GOTOH ${ }^{1}$ \\ ${ }^{1}$ Department of Regenerative Surgery, ${ }^{2}$ Translational Research Center and ${ }^{3}$ Department of Diagnostic Pathology, \\ Fukushima Medical University, School of Medicine, Fukushima 960-1295; ${ }^{4}$ Watari Hospital, \\ Fukushima 960-8141; ${ }^{5}$ Nippon Gene Co., Ltd., Chiyoda, Tokyo 101-0054, Japan
}

Received November 3, 2016; Accepted July 4, 2017

DOI: 10.3892/ijo.2017.4075

\begin{abstract}
Basaloid squamous cell carcinoma of the esophagus (BSCE) is a rare variant of squamous cell carcinoma that is difficult to distinguish from other carcinomas by preoperative endoscopic biopsy because of its histological varieties. Accurate diagnosis is essential for adequate treatment, and the methods proposed so far (e.g., immunohistochemical staining) have limitations. In this study, we tried to identify the characteristic bundles of gene expression in BSCE using comprehensive gene expression analysis (CGEA). Subsequently, we constructed a gene expression scoring system for the proper diagnosis of BSCE. Fifty-seven surgical specimens, including seven BSCEs, obtained from 30 patients who underwent esophagectomy were used for constructing the scoring system. Three hundred and twelve biopsy specimens, including eight BSCEs, obtained from 80 patients and 20 commercially available formalin-fixed paraffin-embedded (FFPE) specimens diagnosed as esophageal cancer, including 13 BSCEs, were used for validation. After our original mathematical extraction algorithm, 75 genes were extracted to distinguish BSCE from non-BSCE. The cumulative converted values (gene expression score) of the respective 75 genes
\end{abstract}

Correspondence to: Professor Mitsukazu Gotoh, Department of Regenerative Surgery, Fukushima Medical University, School of Medicine, 1 Hikarigaoka, Fukushima 960-1295, Japan

E-mail: mgotoh@fmu.ac.jp

Abbreviations: BSC, basaloid squamous cell carcinoma; BSCE, $\mathrm{BSC}$ of the esophagus; CGEA, comprehensive gene expression analysis; FFPE, formalin-fixed paraffin-embedded; AUC, area under the curve; CI, confidence interval; SCC, squamous cell carcinoma; PCR, polymerase chain reaction; NEC, neuroendocrine carcinoma; $\mathrm{CK}$, cytokeratin; SD, standard deviation; ROC, receiver operating characteristic

Key words: basaloid squamous cell carcinoma, comprehensive gene expression analysis, diagnostic method, gene expression scoring system, biopsy specimens from each specimen were obtained and lined up in ascending order to assess the optimal gene expression cut-off score for a definitive diagnosis of BSCE. The validation of this scoring system showed high prediction of the biopsy specimens [area under the curve $(\mathrm{AUC})=0.981 ; 95 \%$ confidence interval $(\mathrm{CI})$ : 0.952-1.000] and the commercially available FFPE specimens (AUC $=0.901 ; 95 \%$ CI: 0.750-1.000). In conclusion, using CGEA in a gene expression scoring system helps in differentiating BSCE from non-BSCE with high accuracy and may contribute in improving BSCE treatment.

\section{Introduction}

Basaloid squamous cell carcinoma (BSC) was first reported by Wain et al (1) to occur in the head and neck region. BSC may occur in various other sites, including esophagus (2), lung (3), anus (4), uterine cervix (5), penis (6), and urinary bladder (7). $\mathrm{BSC}$ of the esophagus (BSCE) is a rare and uncommon variant of squamous cell carcinoma (SCC), with a reported incidence ranging from 1.0 to $8.7 \%(8-16)$ in Japan and 0.4 to $11.3 \%(2,17-24)$ in other countries.

BSCE has six typical components on histology: solid nest with central necrosis, cribriform pattern, ductal differentiation, microcyst and/or trabecular nests, hyaline-like material deposition, and coexistence of SCC components (16). Because of these histological varieties, BSCE is difficult to distinguish from adenoid cystic carcinoma, small cell carcinoma, poorly differentiated SCC, or adenosquamous carcinoma $(2,23,25,26)$. Furthermore, it is even more difficult to diagnose BSCE based on the histological examination of endoscopic biopsy specimens, with a low diagnostic accuracy of only $0-10 \%(23,24,27)$. BSCE has been frequently diagnosed as SCC on endoscopic biopsy specimens, probably because of the fact that BSCE frequently presents as a submucosal tumor-like structure covered with normal epithelium or SCC $(14,15)$. Therefore, sampling multiple and deeper sites is recommended for diagnosis by endoscopic biopsy $(24,27)$. Some diagnostic approaches using immunoreactivity $(2,9,12,16,18,19)$ or polymerase chain reaction (PCR) $(28,29)$ have been reported, but none of these showed high specificity for BSCE. 
The prognosis of BSCE is still controversial. Some studies stated no significant difference between BSCE and SCC $(2,20)$, whereas others stated poorer prognosis of BSCE than that of $\operatorname{SCC}(16,17,23)$. Some authors specified that BSCE shows a poor degree of differentiation, high proliferative activity (2), aggressive biological behavior (16), high telomerase activity (20), and a worse prognosis than that in SCC in advanced cases (30). Meanwhile, other authors mentioned that the treatment for BSCE is similar to that for SCC of the esophagus $(15,23)$. The rarity of and difficulty in the proper diagnosis of BSCE (15) may be responsible for this diversity. Therefore, proper diagnosis is mandatory for analyzing the outcome and determining the suitable treatment for this disease entity.

We have previously reported the use of comprehensive gene expression analysis (CGEA) to identify some disease-specific genes $(31,32)$. The present study aimed to improve the diagnostic accuracy for BSCE by attempting to extract the genes expressed in it. From CGEA of esophagectomy specimens, we constructed, verified, and evaluated a gene expression scoring system for the proper diagnosis of BSCE.

\section{Materials and methods}

Patient selection. We initially enrolled all 113 esophageal cancer patients who underwent esophagectomy and/or endoscopic biopsy at Fukushima Medical University Hospital from January 2008 to July 2015. Among these patients, 14 patients ( 1 in stage 0,4 in stage II, 4 in stage III, 4 in stage IVa, 1 in stage IVb and 1 in unknown stage) were not followed in our department, and one surviving patient (stage II) denied to participate in research. These cases were excluded.

Ethics statement. This study was approved by the ethics committee of Fukushima Medical University (approval no. 1953). Written informed consent was obtained from 98 patients.

Commercially available esophageal specimens. From US Biomax Inc. (Rockville, MD, USA), we purchased 20 formalinfixed paraffin-embedded (FFPE) specimens that were diagnosed to have BSCE components. These FFPE specimens were reviewed by three pathologists before inclusion.

Specimen sampling. Small fractions $(7 \times 7 \mathrm{~mm})$ of the cancerous site and normal mucosa were removed from each surgical specimen and were immediately frozen in liquid nitrogen before performing CGEA. Residual tissue specimens were fixed in formalin and then embedded in paraffin before pathological examination.

For the biopsy specimens, tiny fractions $(3 \times 3 \mathrm{~mm})$ of the esophageal epithelium, including cancerous and normal sites, were obtained endoscopically; they were immediately frozen separately in liquid nitrogen before performing CGEA. Another specimen from near the first biopsy site was obtained endoscopically; it was fixed in formalin and embedded in paraffin before pathological examination. We made an effort to sample multiple and deeper sites by endoscopic biopsy. We ascertained that the frozen specimens for CGEA and the FFPE specimens for pathological examination had identifiable pathological features.

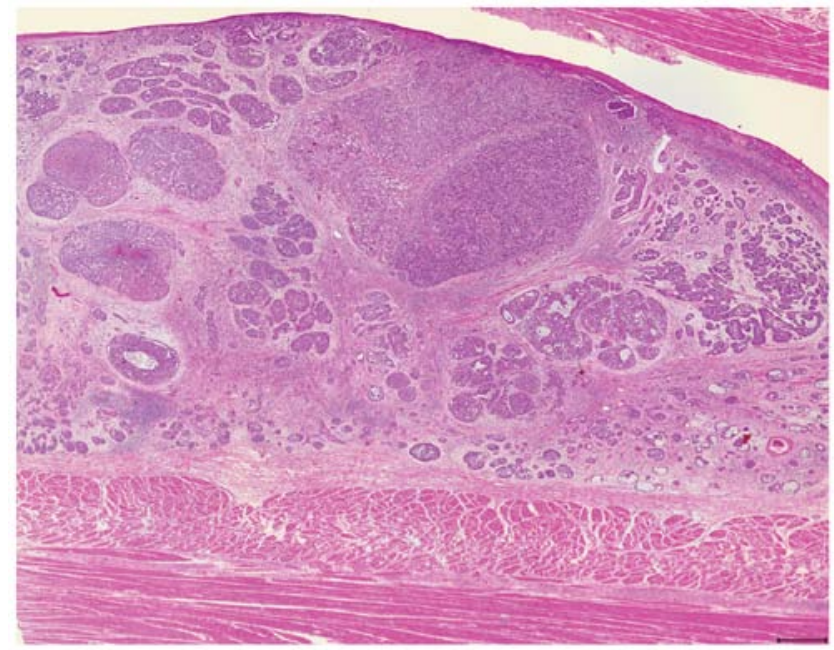

Figure 1. Image of a representative H\&E staining in case 4.

Table I. Sources of specimens for CGEA.

\begin{tabular}{|c|c|c|c|}
\hline Histology & $\begin{array}{c}\text { Surgical } \\
\text { specimens } \\
(\mathrm{N}=57)\end{array}$ & $\begin{array}{l}\text { Biopsy } \\
\text { specimens } \\
(\mathrm{N}=312)\end{array}$ & $\begin{array}{l}\text { Commercially } \\
\text { available } \\
\text { FFPE } \\
\text { specimens } \\
(\mathrm{N}=20)\end{array}$ \\
\hline Normal esophageal tissue & 26 & 229 & 0 \\
\hline SCC & 23 & 51 & 2 \\
\hline BSCE & 7 & 8 & 13 \\
\hline NEC & 1 & 1 & 5 \\
\hline Adenocarcinoma & 0 & 21 & 0 \\
\hline Intraepithelial neoplasia & 0 & 2 & 0 \\
\hline
\end{tabular}

CGEA, comprehensive gene expression analysis; FFPE, formalinfixed paraffin-embedded; SCC, squamous cell carcinoma; BSCE, basaloid squamous cell carcinoma of the esophagus; NEC, neuroendocrine carcinoma.

Pathological review. The surgical, endoscopic biopsy and commercially available FFPE specimens were stained with hematoxylin and eosin and were reviewed by three pathologists (Fig. 1). BSCE was defined using the criteria described by Wain et al (1); the six component histological features reported by Imamhasan et al (16) were also evaluated. In this study, tumors that contained some BSC components within SCC were categorized as BSCE.

Comprehensive gene expression analysis. Frozen specimens were processed for total RNA extraction using Isogen (Nippon Gene Co., Ltd., Tokyo, Japan) and for poly(A)+RNA purification using MicroPoly(A) Purist kit (Ambion, Austin, TX, USA). Commercially available FFPE specimens were processed for total RNA extraction using ISOGEN PB kit (Nippon Gene Co., Ltd.). The human common reference RNA was prepared by mixing equal amounts of total RNA and poly(A)+RNA, which were extracted from 22 human cancer cell lines (A431, A549, AKI, HBL-100, HeLa, HepG2, HL60, IMR-32, Jurket, 
CGEA of 57 surgical specimens, including 7 BSCE specimens

7,379 candidate genes were selected

75 characteristically expressed genes were selected

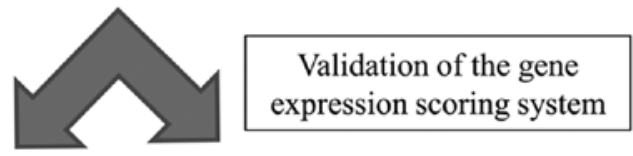

CGEA of 312 endoscopic biopsy specimens, including 8 BSCEs
CGEA of 20 commercially available esophagea FFPE specimens, including 13 BSCEs

Figure 2. Study design. CGEA, comprehensive gene expression analysis; BSCE, basaloid squamous cell carcinoma of the esophagus; FFPE, formalin-fixed paraffin-embedded.

K562, KP4, MKN7, NK-92, Raji, RD, Saos-2, SK-N-MC, SW-13, T24, U251, U937, and Y79).

The DNA microarray that used poly(A)+RNA was named system 1; a set of synthetic polynucleotides (80-mers) representing 31,797 species of human transcript sequences was printed on a glass slide using a custom arrayer. The DNA microarray that used total RNA was named system 2; a set of synthetic polynucleotides (80-mers) representing 14,400 species of human transcript sequences was printed on a glass slide using a custom arrayer. For RNA of the samples, SuperScript II (Invitrogen Life Technologies, Carlsbad, CA, USA) and Cyanine 5-dUTP (Perkin-Elmer Inc., Boston, MA, USA) were used to synthesize labeled cDNA from $2 \mu \mathrm{g}$ of poly(A)+RNA in system 1 and $5 \mu \mathrm{g}$ of total RNA in system 2 . Using the same method for the reference RNA, Cyanine 3-dUTP (Perkin-Elmer Inc.) was used to synthesize labeled cDNA from $2 \mu \mathrm{g}$ of poly(A)+RNA in system 1 and $5 \mu \mathrm{g}$ of total RNA in system 2 .

Hybridization was performed with a Labeling and Hybridization kit (MicroDiagnostic, Tokyo, Japan). Signals were measured using a GenePix 4000B Scanner (Axon Instruments, Inc., Union City, CA, USA) and then processed into the primary expression ratios of the cyanine 5 intensity of each specimen to the cyanine 3 intensity of the human common reference RNA. Each ratio was normalized using GenePix Pro 3.0 software (Axon Instruments, Inc.). The primary expression ratios were converted into $\log 2$ values, which were designated as log ratios or converted value. Data were processed using Microsoft Excel software (Microsoft, Bellevue, WA, USA) and MDI gene expression analysis software package (MicroDiagnostic) (33).

Statistical analysis. Clustering analysis was performed using group average method with an Expression View Pro (MicroDiagnostic).
The cut-off score was determined by receiver operating characteristic (ROC) curve analysis with the aim of validating the gene scoring system. The optimal cut-off score for the definitive diagnosis of BSCE was assessed and determined by area under the ROC curve (AUC) analysis of the maximum values of sensitivity and specificity. ROC curve analysis was performed using the software program SPSS version 23 (SPSS, Inc., Chicago, IL, USA).

Refinement steps to identify candidate genes from CGEA of surgical specimens. Step 1: Genes with fluorescence intensity below the detection limit in two or more of the seven BSCE specimens were excluded. Step 2: The genes with a converted value of $\geq 1$ in at least one of the 57 surgical specimens were selected. Step 3: The mean or average of the converted values of the chosen genes were calculated, and the genes that met the following requirement were selected: average value - converted value $\geq 1$. Step 4 : Clustering analysis was performed on the chosen genes.

Construction of gene expression scoring system for BSCE. Step 5: The mean of the converted values of the genes that were expressed in six specimens of the BSCE cluster was calculated; genes with an average value of $\geq 1$ were selected. Step 6: Genes with fluorescence intensity below the detection limit were excluded in more than half of the non-BSCE specimens. Step 7: The standard deviation (SD) of the converted values of the genes that were expressed in the nonBSCE specimens were calculated; genes with an SD of $<0.5$ were selected. Step 8: Genes that met the following requirement were selected: average value of six specimens in the BSCE cluster - average value of non-BSCE specimens of $\geq 1$. Step 9: A t-test was used to compare the average value of six specimens between the BSCE cluster and the non-BSCE specimens; genes with a P-value of $<0.01$ were selected. 
Table II. Clinicopathologic features of six esophagectomy cases.

\begin{tabular}{|c|c|c|c|c|c|c|c|c|c|c|}
\hline $\begin{array}{l}\text { Age, } \\
\text { sex }\end{array}$ & $\begin{array}{c}\text { Biopsy } \\
\text { diagnosis }\end{array}$ & $\begin{array}{l}\text { Pathologic } \\
\text { diagnosis }\end{array}$ & $\begin{array}{c}\text { Tumor } \\
\text { size }(\mathrm{mm})\end{array}$ & $\begin{array}{l}\text { Tumor } \\
\text { type }\end{array}$ & $\begin{array}{c}\text { Depth of } \\
\text { invasion } \\
\text { (pT) }\end{array}$ & $\begin{array}{l}\text { Lymph node } \\
\text { metastasis } \\
(\mathrm{pN})\end{array}$ & $\begin{array}{l}\text { Lymphatic } \\
\text { invasion } \\
\text { (ly) }\end{array}$ & $\begin{array}{l}\text { Venous } \\
\text { invasion } \\
\text { (v) }\end{array}$ & $\begin{array}{l}\text { UICC } \\
\text { stage }\end{array}$ & Prognosis \\
\hline $168, M$ & ASC & BSCE & 42 & Type 2 & $\mathrm{~T} 1$ & No & 0 & 1 & IA & $\begin{array}{l}58 \text { months-died } \\
\text { (lung metastasis) }\end{array}$ \\
\hline $255, \mathrm{M}$ & SCC & BSCE & 30 & Type 5 & $\mathrm{~T} 1$ & No & 0 & 2 & IA & 60 months-alive \\
\hline $356, \mathrm{M}$ & SCC & BSCE & 25 & Type 3 & $\mathrm{~T} 4$ & N3 & 2 & 2 & IIIC & $\begin{array}{l}19 \text { months-died } \\
\text { (lung metastasis) }\end{array}$ \\
\hline $468, F$ & $\begin{array}{c}\text { SCC (first), } \\
\text { BSCE (second) }\end{array}$ & BSCE & 18 & Type 2 & $\mathrm{~T} 1$ & N0 & 0 & 1 & IA & 37 months-alive \\
\hline $564, \mathrm{M}$ & BSCE & BSCE & 12 & Type 0-IIa & $\mathrm{T} 1$ & N1 & 0 & 0 & IIB & $\begin{array}{l}29 \text { months-alive } \\
\text { (LN metastasis) }\end{array}$ \\
\hline $665, \mathrm{M}$ & BSCE & BSCE, SCC & 5,45 & Type 0 -IIc & $\mathrm{T} 1$ & NO & 0 & 0 & IA & 7 months-alive \\
\hline
\end{tabular}

UICC, Union for International Cancer Control; ASC, adenosquamous carcinoma; SCC, squamous cell carcinoma; BSCE, basaloid squamous cell carcinoma; LN, lymph node.

Step 10: The converted values of the selected genes from all specimens were added as gene expression scores, which were arranged in ascending order.

Study design. First, using CGEA of the surgical specimens, genes that were characteristically expressed in BSCE were identified; subsequently, a gene expression scoring system was constructed to more accurately diagnose BSCE. Second, the accuracy of our scoring system was validated using biopsy and commercially available FFPE specimens. The study design is shown in Fig. 2.

\section{Results}

Pathological diagnosis of the specimens for CGEA. Of the 98 patients, surgical specimens were obtained from 30, endoscopic biopsy specimens from 80 , and both from 12 . Seven cases of BSCE were included in this study, six cases underwent esophagectomy and one case underwent only endoscopic biopsy. We obtained more than one specimen from each individual, and all specimens were subjected to gene expression analysis. The number of specimens that contained enough amount of RNA for CGEA was 369 (57 surgical and 312 endoscopic) (Table I). The surgical specimens comprised 26 normal esophageal tissues, 23 SCCs, seven BSCEs, and one neuroendocrine carcinoma (NEC). Biopsy specimens comprised 229 normal esophageal tissues, 51 SCCs, eight BSCEs, one NEC, 21 adenocarcinomas, and two intraepithelial neoplasias. Commercially available FFPE specimens comprised two SCCs, 13 BSCEs, and five NECs. All commercially available FFPE specimens were also subjected to CGEA.

Clinicopathological characteristics. Patients with BSCE, including five men and one woman, with a mean age of 63 (range, 55-68) years, underwent esophagectomy; their clinicopathological characteristics are listed in Table II. Only three of six patients $(50 \%)$ were diagnosed as having BSCE by preoperative endoscopic biopsy. The mean tumor size was 28.6 (range, 12-45) $\mathrm{mm}$. Based on the seventh Union for International Cancer Control tumor-node-metastasis classification of malignant tumors, the pathological stage was stage I in four patients, stage II in one, and stage III in one. Within a mean follow-up period of 35 (range, 7-60) months, two patients died because of BSCE, one remained alive with recurrence, and three remained alive without recurrence.

Comprehensive gene expression analysis of the surgical specimens. Fig. 3 shows the result of CGEA of 57 surgical specimens, including seven BSCE specimens (one specimen from cases 1, 2,3,5 and three specimens from case 4); 10,027 genes were selected in step 1; 9,004 in step 2; and 7,379 in step 3.

A two-dimensional hierarchical clustering analysis of 7,379 genes yielded three different clusters: the 1) BSCE cluster, which comprised six of the seven BSCE specimens; 2) SCC cluster, which mainly comprised SCC; and 3) normal cluster, which mainly comprised normal esophageal tissue. It was possible to distinguish BSCE specimens from the others using this analysis.

Gene expression scoring system for BSCE. We selected BSCE-specific candidate maker genes and attempted to construct a gene expression scoring system for more accurate diagnosis of BSCE, and 986, 972, 243, and 100 genes were sequentially selected from steps $5,6,7$, and 8 , respectively. Finally, 75 genes were selected in step 9 (Table III) and subjected to extrapolation of the gene expression score, as described in step 10. Our gene expression scoring system, which set the cut-off score at 56.5, very clearly distinguished the seven BSCE specimens from the non-BSCE specimens (Fig. 4).

Validation of the gene expression scoring system. Using CGEA, we calculated 75 gene expression scores, which were arranged in ascending order (Fig. 5). ROC curve analysis of the gene expression scoring system using biopsy specimens 
Table III. Genes characteristically expressed in BSCE based on CGEA of surgical specimens.

\begin{tabular}{|c|c|c|c|}
\hline No. & ID & Symbol & Name \\
\hline 1 & NM_001033568.2 & RHOT1 & Ras homolog family member T1 (RHOT1), transcript variant 1 \\
\hline 2 & NM_015690.4 & STK36 & Serine/threonine kinase 36 (STK36), transcript variant 1 \\
\hline 3 & NM_000915.3 & OXT & Oxytocin/neurophysin I prepropeptide (OXT) \\
\hline 4 & NM_001409.3 & MEGF6 & Multiple EGF-like-domains 6 (MEGF6) \\
\hline 5 & NM_021197.3 & WFDC1 & WAP four-disulfide core domain 1 (WFDC1) \\
\hline 6 & NM_020796.4 & SEMA6A & $\begin{array}{l}\text { Sema domain, transmembrane domain (TM), cytoplasmic domain, (semaphorin) } \\
\text { 6A (SEMA6A) }\end{array}$ \\
\hline 7 & NM_153213.3 & ARHGEF19 & Rho guanine nucleotide exchange factor (GEF) 19 (ARHGEF19) \\
\hline 8 & XM_005261771.3 & PLA2G6 & $\begin{array}{l}\text { Phospholipase A2, group VI (cytosolic, calcium-independent) (PLA2G6), } \\
\text { transcript variant X18 }\end{array}$ \\
\hline 9 & NM_000933.3 & PLCB4 & Phospholipase C, $\beta 4$ (PLCB4), transcript variant 1 \\
\hline 10 & NM_023110.2 & FGFR1 & Fibroblast growth factor receptor 1 (FGFR1), transcript variant 1 \\
\hline 11 & AK055081.1 & & cDNA FLJ30519 fis, clone BRAWH2000859 \\
\hline 12 & NM_000346.3 & SOX9 & SRY (sex determining region Y)-box 9 (SOX9) \\
\hline 13 & NM_025176.4 & NINL & Ninein-like (NINL) \\
\hline 14 & NM_014698.2 & TMEM63A & Transmembrane protein 63A (TMEM63A) \\
\hline 15 & NM_020870.3 & SH3RF1 & SH3 domain containing ring finger 1 (SH3RF1) \\
\hline 16 & NM_001110514.1 & EBF4 & Early B-cell factor 4 (EBF4) \\
\hline 17 & NR_036481.2 & FGD5P1 & $\begin{array}{l}\text { FYVE, RhoGEF and PH domain containing } 5 \text { pseudogene } 1 \text { (FGD5P1), } \\
\text { non-coding RNA }\end{array}$ \\
\hline 18 & NM_005117.2 & FGF19 & Fibroblast growth factor 19 (FGF19) \\
\hline 19 & NM_032192.3 & PPP1R1B & Protein phosphatase 1, regulatory (inhibitor) subunit 1B (PPP1R1B) \\
\hline 20 & NM_020659.3 & TTYH1 & Tweety family member 1 (TTYH1), transcript variant 1 \\
\hline 21 & NM_145804.2 & ABTB2 & Ankyrin repeat and BTB (POZ) domain containing 2 (ABTB2) \\
\hline 22 & NM_194302.3 & CCDC108 & Coiled-coil domain containing 108 (CCDC108), transcript variant 1 \\
\hline 23 & NM_002995.2 & $\mathrm{XCL} 1$ & Chemokine (C motif) ligand 1 (XCL1) \\
\hline 24 & NM_001940.3 & ATN1 & Atrophin 1 (ATN1), transcript variant 2 \\
\hline 25 & AK021565.1 & & cDNA FLJ11503 fis, clone HEMBA1002113 \\
\hline 26 & NM_006941.3 & SOX10 & SRY (sex determining region Y)-box 10 (SOX10) \\
\hline 27 & NM_003222.3 & TFAP2C & Transcription factor AP- $2 \gamma$ (activating enhancer-binding protein $2 \gamma$ ) (TFAP2C) \\
\hline 28 & NM_003963.2 & TM4SF5 & Transmembrane 4 L six family member 5 (TM4SF5) \\
\hline 29 & NM_002180.2 & IGHMBP2 & Immunoglobulin mu-binding protein 2 (IGHMBP2) \\
\hline 30 & NM_015696.4 & GPX7 & Glutathione peroxidase 7 (GPX7) \\
\hline 31 & NM_017789.4 & SEMA4C & $\begin{array}{l}\text { Sema domain, immunoglobulin domain (Ig), transmembrane domain (TM) and } \\
\text { short cytoplasmic domain, (semaphorin) } 4 \mathrm{C} \text { (SEMA4C) }\end{array}$ \\
\hline 32 & NM_178502.3 & DTX3 & Deltex 3, E3 ubiquitin ligase (DTX3), transcript variant 1 \\
\hline 33 & NM_014937.3 & INPP5F & Inositol polyphosphate-5-phosphatase F (INPP5F), transcript variant 1 \\
\hline 34 & NM_001380.4 & DOCK1 & Dedicator of cytokinesis 1 (DOCK1), transcript variant 2 \\
\hline 35 & NM_007081.2 & RABL2B & $\mathrm{RAB}$, member of RAS oncogene family-like $2 \mathrm{~B}$ (RABL2B), transcript variant 2 \\
\hline 36 & AK055044.1 & TARBP1 & TAR (HIV-1) RNA-binding protein 1 (TARBP1) \\
\hline 37 & NM_006312.5 & NCOR2 & Nuclear receptor corepressor 2 (NCOR2), transcript variant 1 \\
\hline 38 & NM_007270.4 & FKBP9 & FK506-binding protein 9, $63 \mathrm{kDa}(\mathrm{FKBP} 9)$, transcript variant 1 \\
\hline 39 & NM_016162.3 & ING4 & Inhibitor of growth family, member 4 (ING4), transcript variant 1 \\
\hline 40 & NM_005937.3 & MLLT6 & Myeloid/lymphoid or mixed-lineage leukemia; translocated to 6 (MLLT6) \\
\hline 41 & AK021700.1 & & cDNA FLJ11638 fis, clone HEMBA1004323 \\
\hline 42 & NM_015662.2 & IFT172 & Intraflagellar transport 172 (IFT172) \\
\hline 43 & NM_032501.3 & ACSS 1 & Acyl-CoA synthetase short-chain family member 1 (ACSS1), transcript variant 1 \\
\hline 44 & NM_016102.3 & TRIM17 & Tripartite motif containing 17 (TRIM17), transcript variant 1 \\
\hline 45 & NM_152753.3 & SCUBE3 & Signal peptide, CUB domain, EGF-like 3 (SCUBE3), transcript variant 1 \\
\hline 46 & NM_133455.3 & EMID1 & EMI domain containing 1 (EMID1), transcript variant 1 \\
\hline
\end{tabular}


Table III. Continued.

\begin{tabular}{|c|c|c|c|}
\hline No. & ID & Symbol & Name \\
\hline 47 & NM_014640.4 & TTLL4 & Tubulin tyrosine ligase-like family member 4 (TTLL4) \\
\hline 48 & NM_001161616.2 & RGL3 & Ral guanine nucleotide dissociation stimulator-like 3 (RGL3), transcript variant 1 \\
\hline 49 & NM_024798.2 & SNX22 & Sorting nexin 22 (SNX22), transcript variant 1 \\
\hline 50 & NM_032781.3 & PTPN5 & $\begin{array}{l}\text { Protein tyrosine phosphatase, non-receptor type } 5 \text { (striatum-enriched) (PTPN5), } \\
\text { transcript variant } 2\end{array}$ \\
\hline 51 & NM_005996.3 & TBX3 & T-box 3 (TBX3), transcript variant 1 \\
\hline 52 & NM_000875.4 & IGF1R & Insulin-like growth factor 1 receptor (IGF1R), transcript variant 1 \\
\hline 53 & NM_178238.3 & PILRB & Paired immunoglobin-like type 2 receptor $\beta$ (PILRB) \\
\hline 54 & NM_152748.3 & KIAA1324L & KIAA1324-like (KIAA1324L), transcript variant 1 \\
\hline 55 & NM_003505.1 & FZD1 & Frizzled class receptor 1 (FZD1) \\
\hline 56 & NM_173812.4 & DPY19L2 & Dpy-19-like 2 (C.elegans) (DPY19L2) \\
\hline 57 & NM_032447.3 & FBN3 & Fibrillin 3 (FBN3) \\
\hline 58 & NM_001987.4 & ETV6 & Ets variant 6 (ETV6) \\
\hline 59 & NM_017563.3 & IL17RD & Interleukin 17 receptor D (IL17RD) \\
\hline 60 & NM_032040.4 & CCDC8 & Coiled-coil domain containing 8 (CCDC8) \\
\hline 61 & NM_018257.2 & PCMTD2 & $\begin{array}{l}\text { Protein-L-isoaspartate (D-aspartate) O-methyltransferase domain containing } 2 \\
\text { (PCMTD2), transcript variant } 1\end{array}$ \\
\hline 62 & NM_152730.5 & TBC1D32 & TBC1 domain family, member 32 (TBC1D32), transcript variant 1 \\
\hline 63 & NM_152739.3 & HOXA9 & Homeobox A9 (HOXA9) \\
\hline 64 & NM_021156.3 & TMX4 & Thioredoxin-related transmembrane protein 4 (TMX4) \\
\hline 65 & NM_002507.3 & NGFR & Nerve growth factor receptor (NGFR) \\
\hline 66 & NM_004776.3 & B4GALT5 & UDP-Gal:betaGlcNAc $\beta$ 1,4-galactosyltransferase, polypeptide 5 (B4GALT5) \\
\hline 67 & NM_015544.2 & TMEM98 & Transmembrane protein 98 (TMEM98), transcript variant 1 \\
\hline 68 & NM_001852.3 & COL9A2 & Collagen, type IX, $\alpha 2$ (COL9A2) \\
\hline 69 & NM_005247.2 & FGF3 & Fibroblast growth factor 3 (FGF3) \\
\hline 70 & NM_002523.2 & NPTX2 & Neuronal pentraxin II (NPTX2) \\
\hline 71 & NM_001853.3 & COL9A3 & Collagen, type IX, $\alpha 3$ (COL9A3) \\
\hline 72 & NM_001851.4 & COL9A1 & Collagen, type IX, $\alpha 1$ (COL9A1), transcript variant 1 \\
\hline 73 & NM_014289.3 & CAPN6 & Calpain 6 (CAPN6), \\
\hline 74 & NM_002336.2 & LRP6 & Low-density lipoprotein receptor-related protein 6 (LRP6) \\
\hline 75 & NM_001692.3 & ATP6V1B1 & ATPase, $\mathrm{H}^{+}$transporting, lysosomal 56/58 kDa, V1 subunit B1 (ATP6V1B1) \\
\hline
\end{tabular}

yielded an optimal cut-off score of 40.5, with an AUC of 0.981 , sensitivity of $87.5 \%$, and specificity of $99.0 \%$ (Fig. 6A).

By the same procedure, ROC curve analysis of the gene expression scoring system using commercially available FFPE specimens, including 13 BSCE, yielded an optimal cut-off score of 34.9, with AUC of 0.901, sensitivity of 92.3\%, and specificity of $71.4 \%$ (Fig. 6B).

\section{Discussion}

Using CGEA of esophagectomy specimens, we identified the 75 genes that were characteristically expressed in BSCE to construct a gene expression scoring system, which made it possible to distinguish BSCE from non-BSCE in biopsy and commercially available FFPE specimens with high sensitivity and specificity. To our knowledge, this is the first report to show an accurate diagnostic modality that could significantly contribute in improving the diagnosis and treatment of BSCE.
Diagnosing BSCE using endoscopic biopsy specimens is difficult, with a reported diagnostic accuracy of only $0 \%$ to $10 \%(23,24,27)$. We too were unable to accurately diagnose BSCE using preoperative endoscopic biopsy in three of six surgical patients. To overcome this difficulty, immunohistochemical staining was performed. Cytokeratin (CK) subtypes, including CK13 (12), CK14 (16), and CK19 $(9,12,19)$, were attempted, but they failed to show specific properties, as did p53 and $\mathrm{Rb}$ protein $(12,34,35)$. On the other hand, a combination of immunohistochemical staining and PCR analysis was previously tested for differential diagnosis: Bcl-2 expression together with c-myc amplification was demonstrated to be more frequent in BSCE than in SCC (28), but the specificity of this test was low (43.5\%). In this study, we identified the 75 genes that were characteristically expressed in BSCE. None of these genes were mentioned in previous reports. Of 75 genes, collagen related genes (COL9A2,COL9A3,COL9A1) and fibroblast growth factor related genes (FGF19, FGF3) 


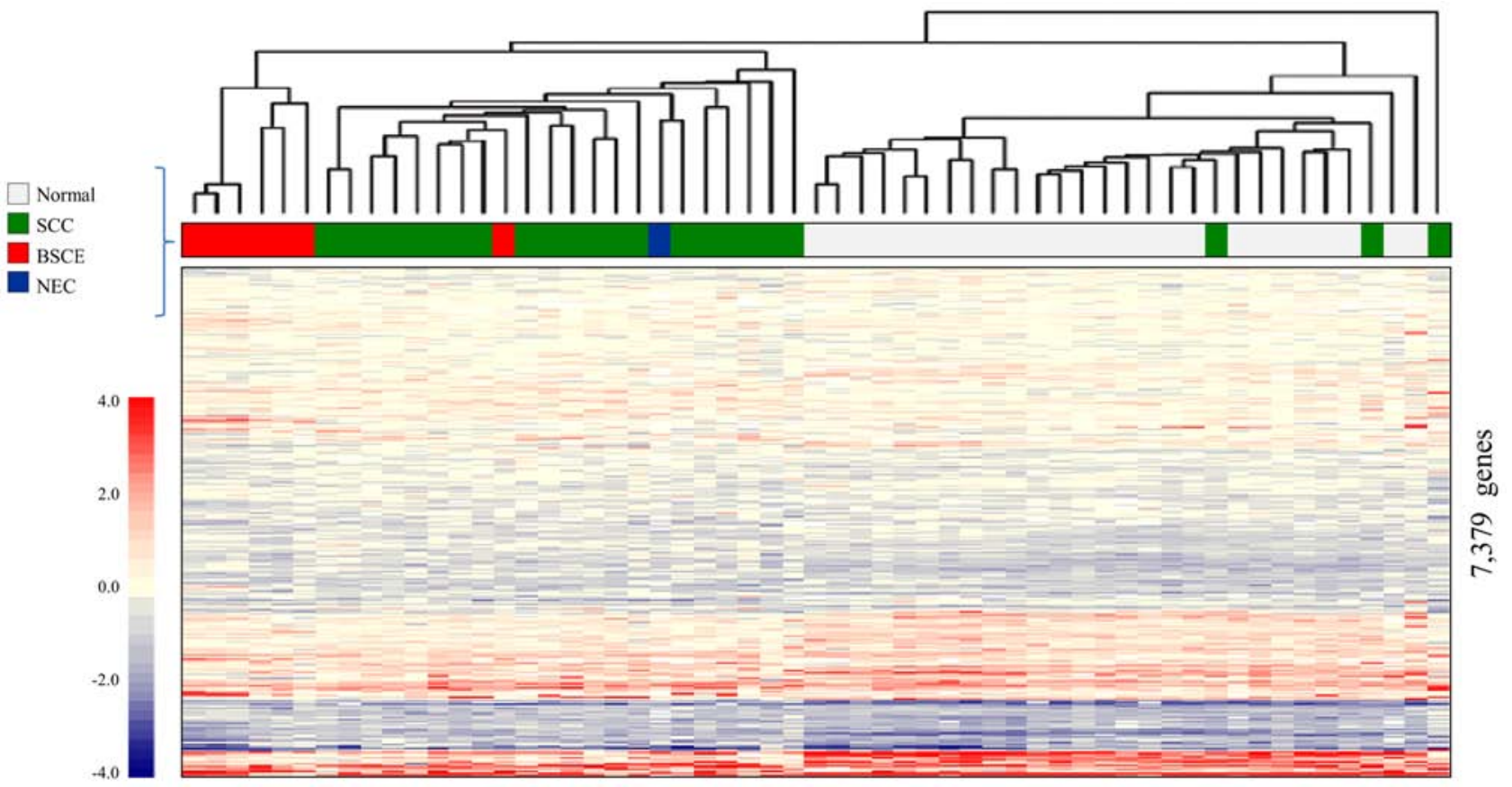

Figure 3. Comprehensive gene expression analysis of 57 surgical specimens. Specimens and genes are aligned in the order defined by the results of the clustering analysis. The dendrogram indicates the relationship among the specimens based on dissimilarity coefficients calculated through clustering analysis. The color bar at the left side of the figure represents the grades of the relative expression levels: increase (red), decrease (blue). SCC, squamous cell carcinoma; BSCE, basaloid squamous cell carcinoma of the esophagus; NEC, neuroendocrine carcinoma.

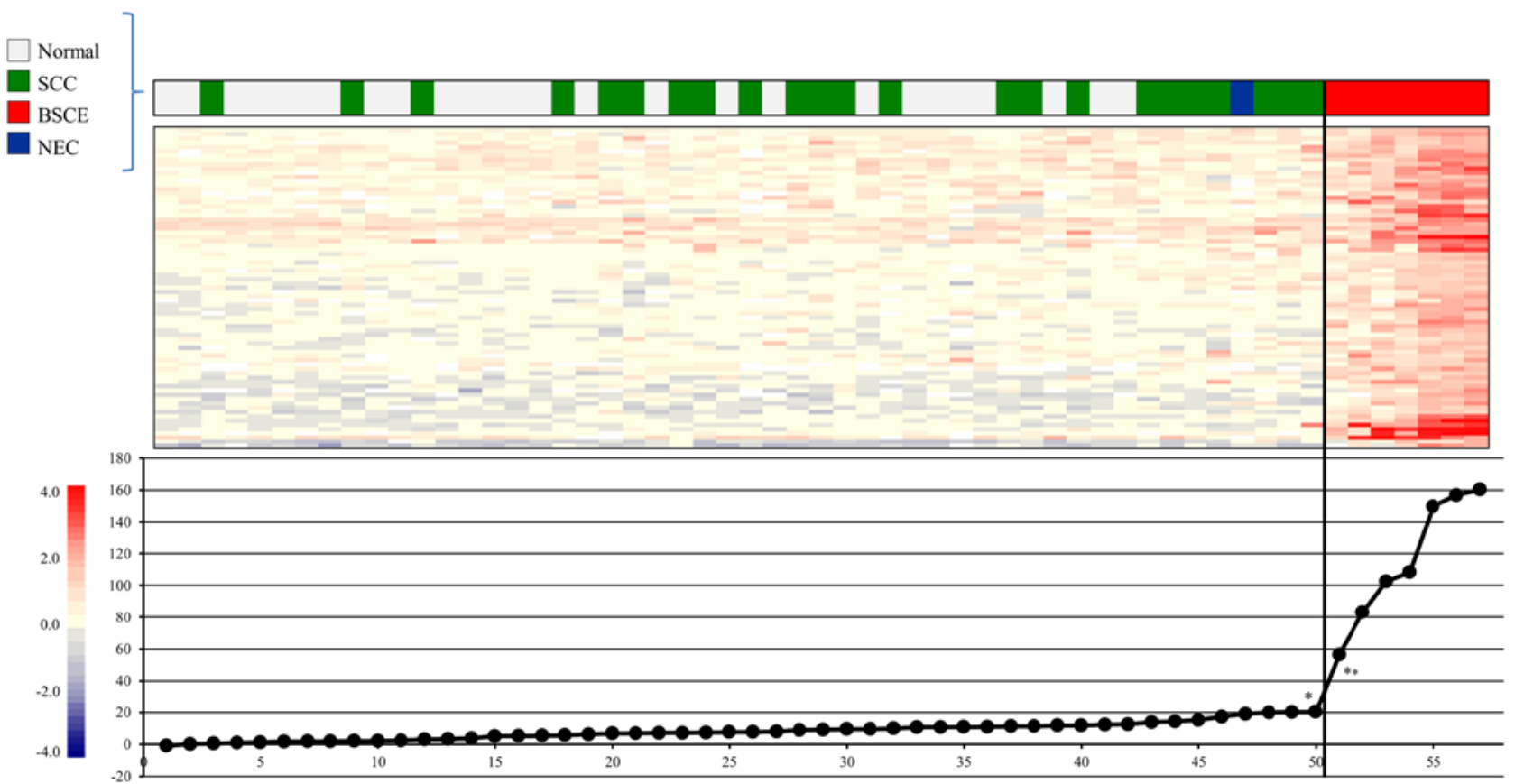

Figure 4. Gene expression scoring system for BSCE using surgical specimens. Line graph depicts the gene expression score. Black vertical line indicates the border between BSCE and non-BSCE. The color bar at the left side of the figure represents the grades of the relative expression levels: increase (red), decrease (blue). X-axis of the graph indicates a number of specimens, and y-axis indicates a gene expression score. *20.2 and ** 56.5. SCC, squamous cell carcinoma; BSCE, basaloid squamous cell carcinoma of the esophagus; NEC, neuroendocrine carcinoma.

might be concerning the characteristics of BSCE based on the association with genes identified in this study.

In one study, comprehensive gene expression profiling was performed for endoscopic biopsy specimens of esophageal SCC (36). However, CGEA in our institution is different from that in the other institution. We had previously extracted some disease-specific genes through the CGEA system at our institution $(31,32)$. Our CGEA has three features: 1) it can analyze small samples, like endoscopic biopsy specimens; 2) it can be performed without RNA amplification; and 3) the gene expression ratio of all types of samples can be compared with human common reference RNA. Comprehensive gene 


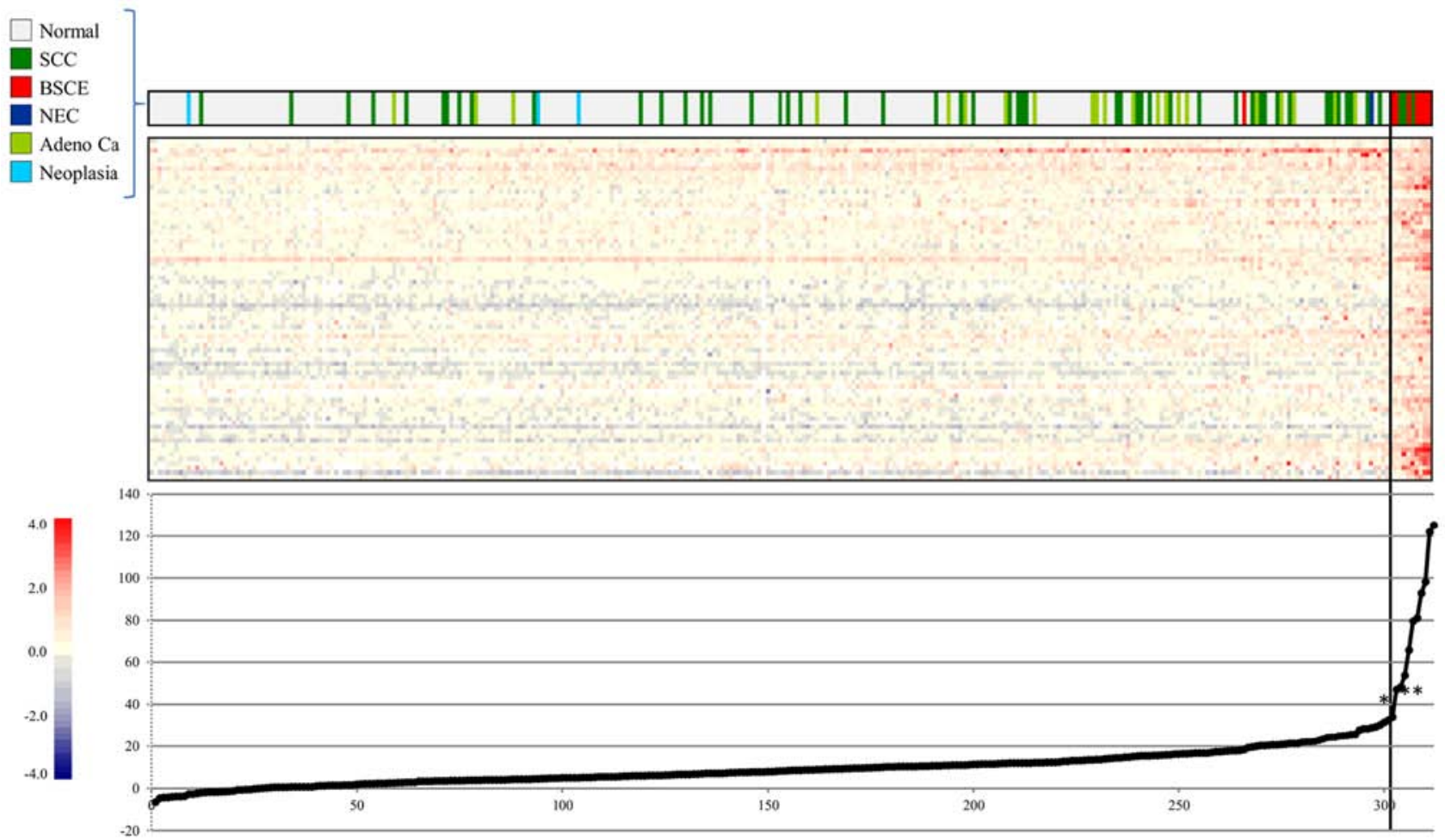

Figure 5. Validation of gene expression scoring system using endoscopic biopsy specimens. Black vertical line indicates the optimal cut-off score through ROC curve analysis. X-axis of the graph indicates a number of specimens, and y-axis indicates a gene expression score. ${ }^{*} 34.0$ and ${ }^{* *} 47.0$. ROC, receiver operating characteristic; SCC, squamous cell carcinoma; BSCE, basaloid squamous cell carcinoma of the esophagus; NEC, neuroendocrine carcinoma.
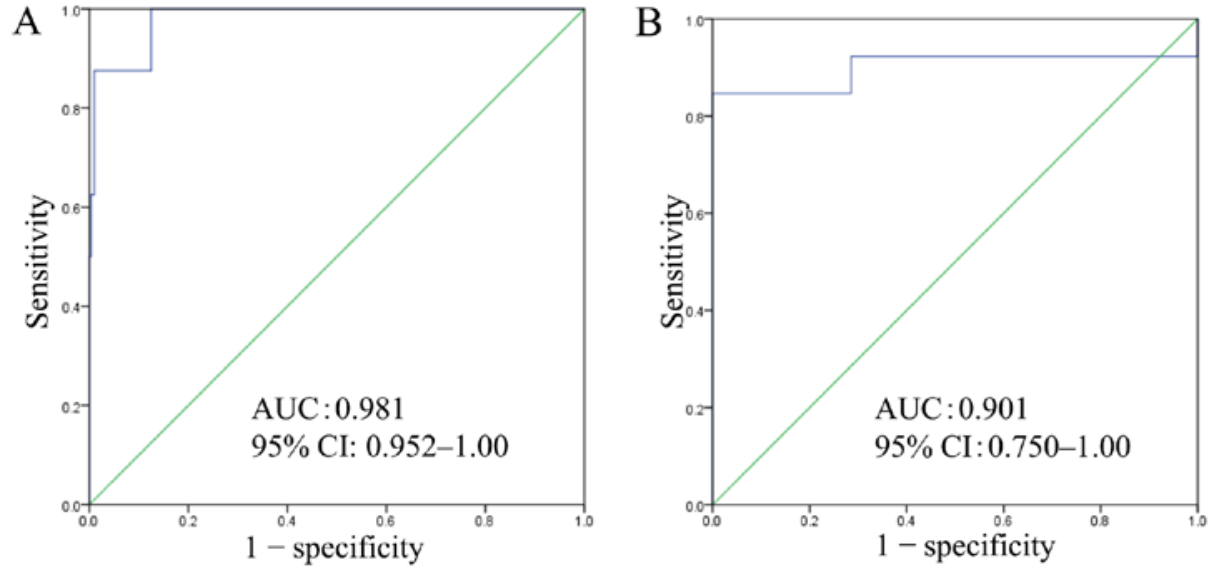

Figure 6. ROC curve analysis. (A) For the endoscopic biopsy specimens, the optimal cut-off score is 40.5 . AUC is 0.981 , with a sensitivity of $87.5 \%$ and a specificity of $99.0 \%$. (B) For the commercially available FFPE specimens, the optimal cut-off score is 34.9 . AUC is 0.901 , with a sensitivity of $92.3 \%$ and a specificity of 71.4\%. ROC, receiver operating characteristic; AUC, area under the curve; CI, confidence interval; FFPE, formalin-fixed paraffin-embedded.

expression analysis is done to compare the expression levels of the human common reference RNA which was prepared from 22 human cancer cell lines. Profiles were obtained even from the BSC samples comprising SCC components. A group of genes specific for BSC were selected by comparing BSC containing SCC component with non-BSC (SCC). A group of genes that were expressed in $\mathrm{SCC}$ components were eliminated by selection process for the genes specific for BSC. Therefore, the group of genes specific for BSC can distinguish between the BSC and non-BSC even though BSC samples included SCC components. Introducing of the scoring system enabled us to differentiate BSC from non-BSC if the sample contains a limited portion of BSC with SCC components. In this study, we selected 75 genes for constructing a gene expression scoring system for the proper diagnosis of BSCE. There have been no reports on studies in which a gene expression scoring system was constructed to diagnose cancers. This scoring system is a novel, precise, and powerful tool for diagnosing BSCE in both endoscopic biopsy and FFPE specimens.

There are several limitations in this study. First, the biopsy specimens obtained for histology and CGEA were not identical, although we tried as much as possible to choose specimens that were adjacent to each other. In addition, biopsy samples might not hit the component of BSC for accurate 
diagnosis by pathological and genetical analysis. Thus, biopsy samples should be obtained from multiple sites in deep portion of tumor to obtain histological characteristics of BSC. In contrast, with this method, we are able to diagnose BSC from very small amount of specimens as long as it contains BSC component. Second, the parameters of processing the commercially available FFPE specimens (i.e., interval between resection and fixation, duration of fixation) were not controlled. Third, the cut-off scores varied among the sources (surgical, endoscopic biopsy, and FFPE specimens); this may have affected the attainment of reasonable specificity and sensitivity. In this study, the number of patients was too small to enable comparison of the prognoses between BSCE and SCC. These limitations should be addressed using a larger number of cases in the future. Nevertheless, we believe that this method elucidates the proper diagnosis of very rare cases of BSCE. Furthermore, it may be able to clarify whether the prognosis of patients with BSCE is similar to or poorer than that of patients with SCC. Lastly, recently (December 1, 2016) International Cell Line Authentication Committee released Version 8.0 of database of cross-contaminated or misidentified cell lines (37), in which we found five cell lines (AKI human melanoma, HBL-100 human breast carcinoma, human gastric carcinoma MKN-7, SK-N-MC human neuroblastoma and U937 lymphoma histiocytic cells) among our 22 reference cell lines have been contaminated with HeLa cervical adenocarcinoma cells, human cells of unknown origin, a cell line of unknown origin, human Sarcoma (Ewing's) cells and a cell line of unknown origin, respectively. Even with this condition of reference cell lines it is obvious that our results would not be affected since we only used a relative ratio of BSCE against SCC, but not an absolute ratio to reference cell lines in order to select the responsible genes for the scoring system.

In conclusion, using CGEA of esophagectomy specimens, we identified 75 genes that are characteristically expressed in BSCE; a gene expression scoring system constructed from these data enabled us to distinguish BSCE from non-BSCE with high sensitivity and specificity, even on endoscopic biopsy specimens. We believe that this scoring system can be a novel method that may significantly contribute to improving the diagnostic accuracy for BSCE.

\section{Acknowledgements}

This work was partially supported by grants for translational research programs from the New Energy and Industrial Technology Development Organization (Tokyo, Japan) and Fukushima Prefecture. The authors would like to thank Enago (www.enago.jp) for the English language review.

\section{References}

1. Wain SL, Kier R, Vollmer RT and Bossen EH: Basaloidsquamous carcinoma of the tongue, hypopharynx, and larynx: Report of 10 cases. Hum Pathol 17: 1158-1166, 1986.

2. Sarbia M, Verreet P, Bittinger F, Dutkowski P, Heep H, Willers R and Gabbert HE: Basaloid squamous cell carcinoma of the esophagus: Diagnosis and prognosis. Cancer 79: 1871-1878, 1997.

3. Brambilla E, Moro D, Veale D, Brichon PY, Stoebner P, Paramelle B and Brambilla C: Basal cell (basaloid) carcinoma of the lung: A new morphologic and phenotypic entity with separate prognostic significance. Hum Pathol 23: 993-1003, 1992.
4. Chetty R, Serra S and Hsieh E: Basaloid squamous carcinoma of the anal canal with an adenoid cystic pattern: Histologic and immunohistochemical reappraisal of an unusual variant. Am J Surg Pathol 29: 1668-1672, 2005.

5. Brainard JA and Hart WR: Adenoid basal epitheliomas of the uterine cervix: A reevaluation of distinctive cervical basaloid lesions currently classified as adenoid basal carcinoma and adenoid basal hyperplasia. Am J Surg Pathol 22: 965-975, 1998.

6. Cubilla AL, Reuter VE, Gregoire L, Ayala G, Ocampos S, Lancaster WD and Fair W: Basaloid squamous cell carcinoma: a distinctive human papilloma virus-related penile neoplasm: a report of 20 cases. Am J Surg Pathol 22: 755-761, 1998.

7. Vakar-López F and Abrams J: Basaloid squamous cell carcinoma occurring in the urinary bladder. Arch Pathol Lab Med 124: $455-459,2000$.

8. Takubo K, Mafune K, Tanaka Y, Miyama T and Fujita K: Basaloid-squamous carcinoma of the esophagus with marked deposition of basement membrane substance. Acta Pathol Jpn 41: 59-64, 1991.

9. Abe K, Sasano H, Itakura Y, Nishihira T, Mori S and Nagura H: Basaloid-squamous carcinoma of the esophagus. A clinicopathologic, DNA ploidy, and immunohistochemical study of seven cases. Am J Surg Pathol 20: 453-461, 1996.

10. Koide N, Koike S, Adachi W, Amano J, Usuda N and Nagata T: Immunohistochemical expression of bcl-2 protein in squamous cell carcinoma and basaloid carcinoma of the esophagus. Surg Today 27: 685-691, 1997.

11. Kawahara K, Makimoto K, Maekawa T, Yamamoto S, Shiraishi T, Takahashi S, Shirakusa T, Nakayama Y and Kikuchi M: An immunohistochemical examination of basaloid squamous cell carcinoma of the esophagus: Report of a case. Surg Today 31: 655-659, 2001.

12. Ohashi K, Horiguchi S, Moriyama S, Hishima T, Hayashi Y, Momma K, Hanashi T, Izumi Y, Yoshida M and Funata N: Superficial basaloid squamous carcinoma of the esophagus. A clinicopathological and immunohistochemical study of 12 cases. Pathol Res Pract 199: 713-721, 2003.

13. Yoshioka S, Tsujinaka T, Fujitani K and Kawahara K: Prognostic analysis of four cases of basaloid cell carcinoma of the esophagus and 60 reported cases in Japan. Jpn J Gastroenterol Surg 37: 290-295, 2004

14. Kobayashi Y, Nakanishi Y, Taniguchi H, Sekine S, Igaki H, Tachimori Y, Kato H, Matsubara H, Okazumi S and Shimoda T: Histological diversity in basaloid squamous cell carcinoma of the esophagus. Dis Esophagus 22: 231-238, 2009.

15. Saito S, Hosoya Y, Zuiki T, Hyodo M, Lefor A, Sata N, Nagase M, Nakazawa M, Matsubara D, Niki T, et al: A clinicopathological study of basaloid squamous carcinoma of the esophagus. Esophagus 6: 177-181, 2009.

16. Imamhasan A, Mitomi H, Saito T, Hayashi T, Takahashi M, Kajiyama Y and Yao T: Immunohistochemical and oncogenetic analyses of the esophageal basaloid squamous cell carcinoma in comparison with conventional squamous cell carcinomas. Hum Pathol 43: 2012-2023, 2012.

17. Zhang XH, Sun GQ, Zhou XJ, Guo HF and Zhang TH: Basaloid squamous carcinoma of esophagus:a clinicopathological, immunohistochemical and electron microscopic study of sixteen cases. World J Gastroenterol 4: 397-403, 1998.

18. Cho KJ, Jang JJ, Lee SS and Zo JI: Basaloid squamous carcinoma of the oesophagus: A distinct neoplasm with multipotential differentiation. Histopathology 36: 331-340, 2000.

19. Huang Z, Shen Y, Liang Y and Wu X: Basaloid squamous cell carcinoma of the esophagus: An immunohistochemical study of 8 cases. Chin Med J (Engl) 114: 1084-1088, 2001.

20. Lam KY, Law S, Luk JM and Wong J: Oesophageal basaloid squamous cell carcinoma: A unique clinicopathological entity with telomerase activity as a prognostic indicator. J Pathol 195: 435-442, 2001

21. Klaase JM, Hulscher JBF, Offerhaus GJA, ten Kate FJ, Obertop H and van Lanschot JJ: Surgery for unusual histopathologic variants of esophageal neoplasms: A report of 23 cases with emphasis on histopathologic characteristics. Ann Surg Oncol 10: 261-267, 2003.

22. Li TJ, Zhang YX, Wen J, Cowan DF, Hart J and Xiao SY: Basaloid squamous cell carcinoma of the esophagus with or without adenoid cystic features. Arch Pathol Lab Med 128: 1124-1130, 2004

23. Chen SB, Weng HR, Wang G, Yang JS, Yang WP, Li H, Liu DT and Chen YP: Basaloid squamous cell carcinoma of the esophagus. J Cancer Res Clin Oncol 138: 1165-1171, 2012. 
24. Zhang BH, Cheng GY, Xue Q, Gao SG, Sun KL, Wang YG, $\mathrm{Mu} \mathrm{JW}$ and He J: Clinical outcomes of basaloid squamous cell carcinoma of the esophagus: A retrospective analysis of 142 cases. Asian Pac J Cancer Prev 14: 1889-1894, 2013.

25. Akagi I, Miyashita M, Makino H, Nomura T, Ohkawa K and Tajiri T: Basaloid squamous cell carcinoma of the esophagus: Report of two cases. J Nippon Med Sch 75: 354-360, 2008.

26. Nishimura W, Naomoto Y, Hamaya K, Toda S, Miyagi K and Tanaka N: Basaloid-squamous cell carcinoma of the esophagus: Diagnosis based on immunohistochemical analysis J Gastroenterol Hepatol 16: 586-590, 2001.

27. Kato T, Morita T, Fujita M, Miyasaka Y, Horita S, Watanabe Y and Kato H: Basaloid-squamous carcinoma of the esophagus: Report of a case. Surg Today 30: 163-167, 2000.

28. Sarbia M, Loberg C, Wolter M, Arjumand J, Heep H, Reifenberger $\mathrm{G}$ and Gabbert HE: Expression of Bcl-2 and amplification of c-myc are frequent in basaloid squamous cell carcinomas of the esophagus. Am J Pathol 155: 1027-1032, 1999.

29. Bellizzi AM, Woodford RL, Moskaluk CA, Jones DR, Kozower BD and Stelow EB: Basaloid squamous cell carcinoma of the esophagus: Assessment for high-risk human papillomavirus and related molecular markers. Am J Surg Pathol 33: $1608-1614,2009$.

30. Arai T, Aida J, Nakamura KI, Ushio Y and Takubo K: Clinicopathologic characteristics of basaloid squamous carcinoma of the esophagus. Esophagus 8: 169-177, 2011.

31. Miyamoto $\mathrm{K}$, Iwadate $\mathrm{M}$, Yanagisawa $\mathrm{Y}$, Ito $\mathrm{E}$, Imai $\mathrm{J}$, Yamamoto M, Sawada N, Saito M, Suzuki S, Nakamura I, et al: Cathepsin L is highly expressed in gastrointestinal stromal tumors. Int J Oncol 39: 1109-1115, 2011.
32. Okabe N, Ezaki J, Yamaura T, Muto S, Osugi J, Tamura H, Imai J, Ito E, Yanagisawa Y, Honma R, et al: FAM83B is a novel biomarker for diagnosis and prognosis of lung squamous cell carcinoma. Int J Oncol 46: 999-1006, 2015.

33. Miura A, Honma R, Togashi T, Yanagisawa Y, Ito E, Imai J, Isogai T, Goshima N, Watanabe S and Nomura N: Differential responses of normal human coronary artery endothelial cells against multiple cytokines comparatively assessed by gene expression profiles. FEBS Lett 580: 6871-6879, 2006.

34. Owonikoko T, Loberg C, Gabbert HE and Sarbia M: Comparative analysis of basaloid and typical squamous cell carcinoma of the oesophagus: A molecular biological and immunohistochemical study. J Pathol 193: 155-161, 2001.

35. Baba Y, Ishimoto T, Harada K, Kosumi K, Murata A, Miyake K, Hiyoshi Y, Kurashige J, Iwatsuki M, Iwagami S, et al: Molecular characteristics of basaloid squamous cell carcinoma of the esophagus: analysis of KRAS, BRAF, and PIK3CA mutations and LINE-1 methylation. Ann Surg Oncol 22: 3659-3665, 2015.

36. Motoori M, Takemasa I, Yamasaki M, Komori T, Takeno A, Miyata H, Takiguchi S, Fujiwara Y, Yasuda T, Yano M, et al: Prediction of the response to chemotherapy in advanced esophageal cancer by gene expression profiling of biopsy samples. Int J Oncol 37: 1113-1120, 2010.

37. International Cell Line Authentication Committee: Register of Misidentified Cell Lines, version 8.0. December 1, 2016. http://iclac.org/databases/cross-contaminations/. 